\title{
Errata :
}

\section{HLA studies in brucellar spondylitis}

\author{
G.S. ALARCÓN, E. GOTUZZO, S.A. HINOSTROZA, \\ C. CARRILLO, T.S. BOCANEGRA, L.R. ESPINOZA \\ in Vol. $4 \mathrm{~N}^{\circ}$ 3, p.p. 312-314.
}

Our readers are requested to note the correction to the last paragraph of this article wich should read as follows :

The present stydy was thus conducted in patients with spondylitis, a form of articular brucellosis which tends to be chronic and may lead to destructive disease. The lack of association between B27 and B7-CREG phenotypes and the occurrence of brucellar spondylitis may suggest that an as yet unidentified, a unique HLA specificity not identified by the available panel of antisera and likely to be relatively selective for the population studied, -a "native" antigen could be the important one(s). The significant increased frequency of $\mathrm{Bx}$ in the spondylitic patients as compared to the controls may relate to such an antigen. Furthermore, a more selective sample of articular brucellosis patients, namely, the ones with reactive arthritis, may need to be studied in order to find an association.

\section{Acute pseudoseptic arthritis and palmoplantar pustulosis}

\author{
A.M. CHAMOT*, B. VION**, J.C. GERSTER* \\ in Vol. $5 \mathrm{~N}^{\circ} 1$, p.p. 118-123.
}

Kindly note the corrections to figures 2 and 3 from those of the previous issue: 


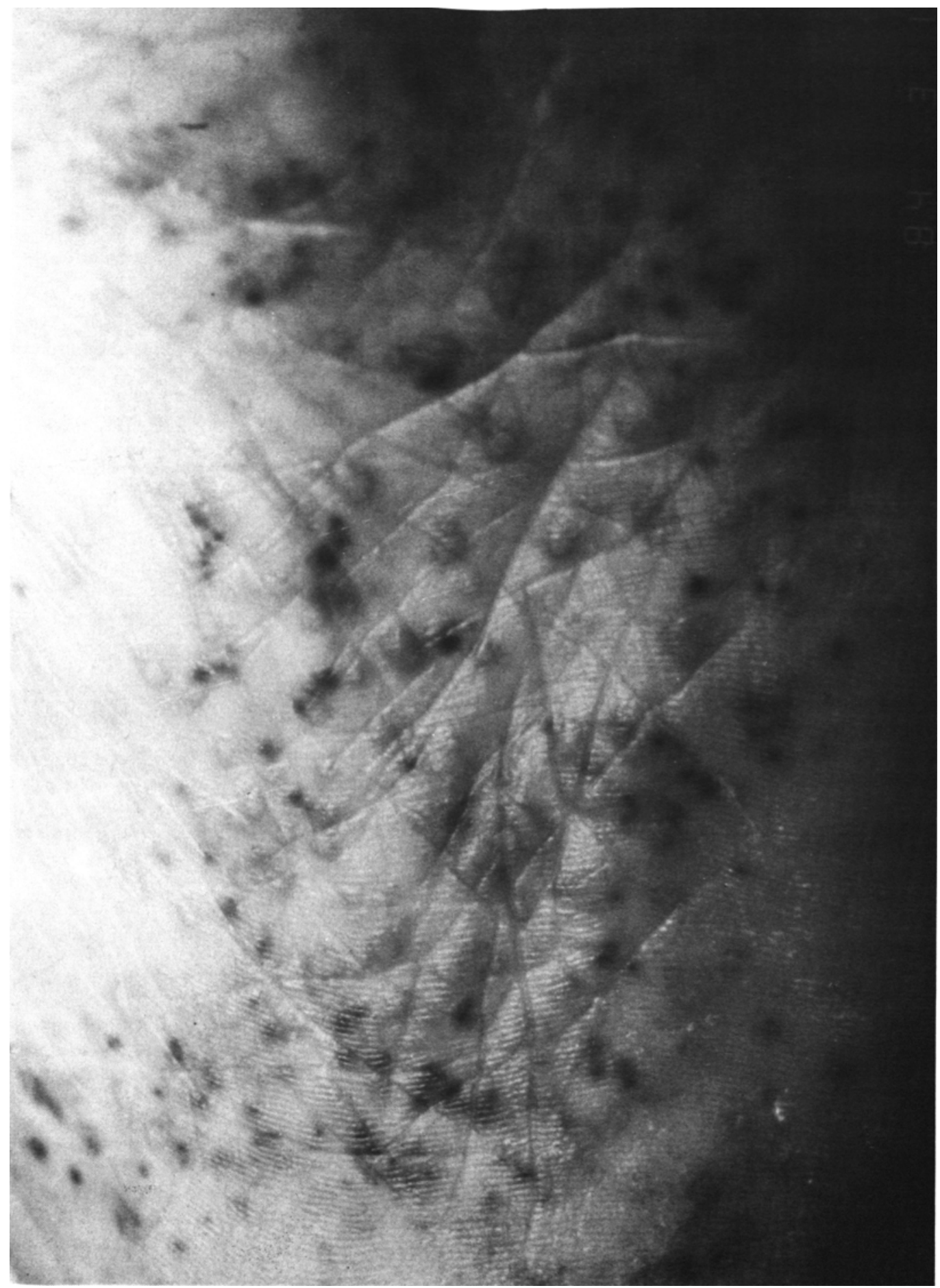

Fig. 2: Pustulosis of a sole 


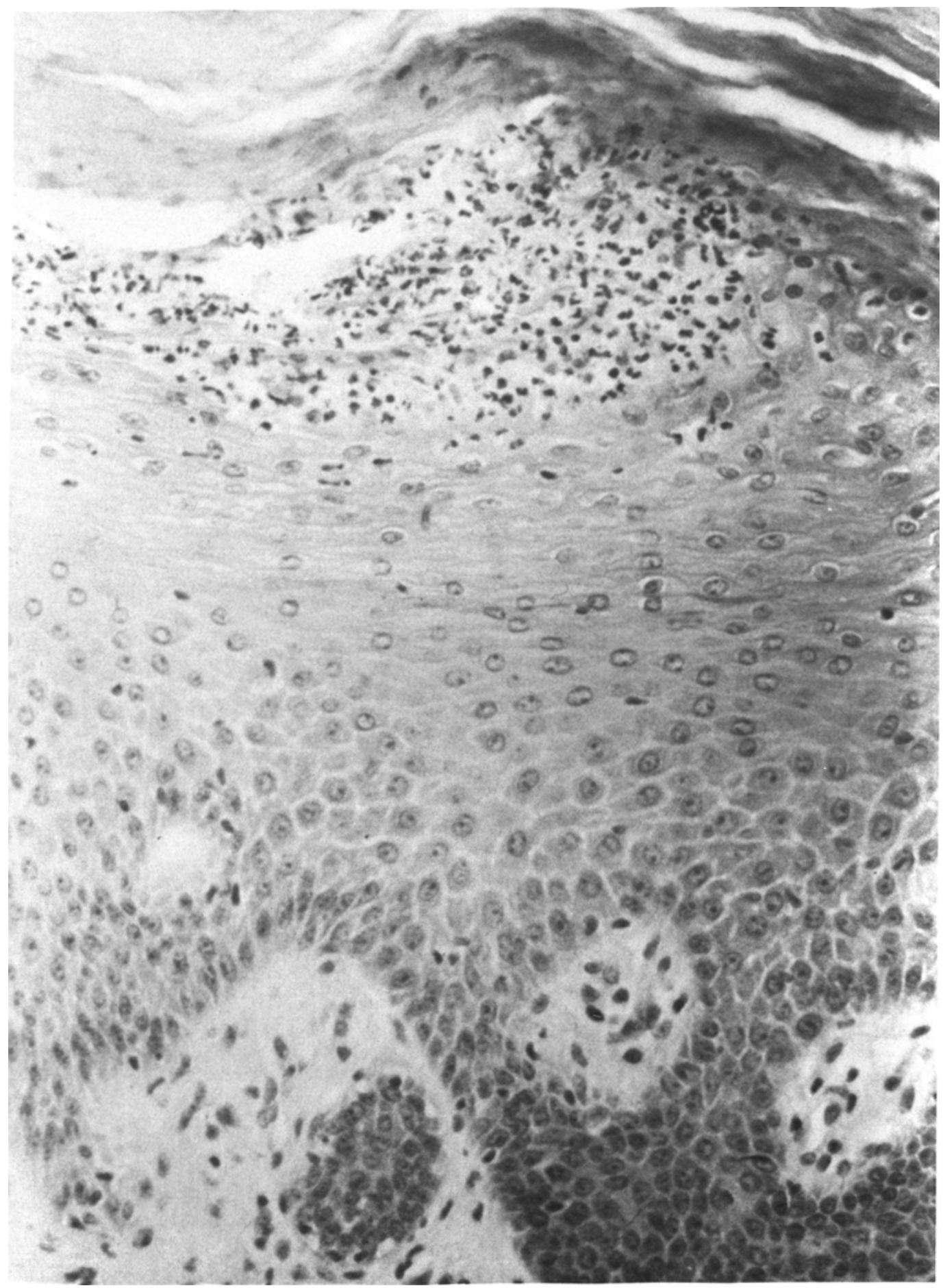

Fig. 3 : Subcorneal pustule with many polymorphonuclear leukocytes surrounded with multilocular pustules. 